Информация об авторах

Рогачев Алексей Фруминович, профессор кафедры "Математическое моделирование и информатика" Волгоградского государственного аграрного университета (РФ, 400002, г. Волгоград, пр. Университетский, д.26), доктор технических наук, професcop https://orcid.org/0000-0001-6483-6091, rafr@mail.ru

Мелихова Елена Валентиновна, доктор технических наук, заведующий кафедрой «Математическое моделирование и информатика» Волгоградского государственного аграрного университета (РФ, 400002, г. Волгоград, пр. Университетский, д.26), https://orcid.org/0000-0002-4041-4270, melv07@mail.ru

DOI: 10.32786/2071-9485-2021-04-38

\title{
CONSTRUCTION OF CHANNEL PLATES USING COMPOSITE
} REINFORCEMENT

\author{
S. Ya. Semenenko, S. S. Marchenko, D.P. Ar'kov \\ Volgograd State Agrarian University, Volgograd
}

Received 0909.2021

Submitted 08.11.2021

\section{Summary}

The high degree of deterioration of water supply facilities of state irrigation systems requires modern engineering solutions that reduce repair costs and improve the quality of reclamation infrastructure. The study considers the possibility of using non-metallic composite reinforcement for reinforcing the protective layer of anti-filtration clothing of the main channels of irrigation systems and provides recommendations for its use.

Abstract
Deals with the problem of using composite reinforcement in hydraulic engineering construction, namely, when installing anti-filtration clothing of main irrigation canals of state irrigation and irrigation systems. Data on water losses during transportation in irrigation systems, as well as the need for anti-filtration clothing of irrigation systems of the Volgograd and Astrakhan regions are presented. The positive and negative aspects of the use of non-metallic composite reinforcement (NCR) are described, comparative strength calculations of plates with reinforcement with non-metallic composite reinforcement of different production technologies are given, conclusions are drawn about the prospects of using non-metallic composite reinforcement in hydraulic engineering construction. Introduction. The water strategy of the Russian Federation requires to exclude inappropriate losses of fresh water, which is hindered by such factors as critical wear of reclamation systems, deterioration of the condition of reclaimed land, especially in the zone of the main transportation network. A well-proven anti-filtration technology is the use of multilayer anti-filtration clothing, including an anti-filtration polymer and a protective reinforced concrete layer. The high demand for reinforced concrete elements of anti-filtration protection requires the use of engineering solutions to reduce their cost and extend their service life, which is hindered by the high price of steel. Thus, research aimed at replacing expensive steel with cheaper and more practical analogues in hydraulic engineering construction is of practical interest. Object. The object of the study is a protective layer of anti-filtration clothing of the main channels of irrigation systems. Goal - Determination of the possibility of using non-metallic composite reinforcement for reinforcing channel plates used as a protective layer in the channels of irrigation systems. Materials and methods. The work used a general scientific methodology with methods of empirical (observation, description, comparison, measurement) and theoretical (analysis and synthesis) levels. Results and conclusions. Based on the strength characteristics of non-metallic composite reinforcement, using the accepted methods, the selection of sections of working reinforcement for plates of the most popular form factor was made, the most suitable type of non-composite reinforcement was determined. The advantage of using non-metallic composite reinforcement for this type of hydraulic structures is shown and recommendations for its use are given.

Key words: anti-filtration cladding, irrigation system, main channel, non-metallic composite reinforcement. 


\title{
***** H3BECTYЯ ***** \\ НИЖНЕВОАЖСКОГО АГРОУНИВЕРСИТЕТСКОГО КОМПАЕКСА: \\ НАУКА И ВЫСШЕЕ ПРОФЕССИОНААЬНОЕ ОБРАЗОВАНИЕ
}

Citation. Semenenko S. Ya., Marchenko S. S., Arkov D. P. Construction of channel plates using composite reinforcement. Proc. of the Lower Volga Agro-University Comp. 2021. 4(64). 378-390 (in Russian). DOI: 10.32786/2071-9485-2021-04-38.

Author's contribution. All the authors of this study were directly involved in the collection and preparation of the material, calculations and analysis of the results of this study. All the authors of this article have read and approved the submitted final version.

Conflict of interest. The authors declare that there is no conflict of interest.

\section{УДК 626:691.328 \\ КОНСТРУИРОВАНИЕ КАНАЛЬНЫХ ПЛИТ С ПРИМЕНЕНИЕМ КОМПОЗИТНОЙ АРМАТУРЫ}

\author{
С. Я. Семененко, доктор сельскохозяйственных наук, ведущий научный сотрудник \\ С. С. Марченко, кандидат технических наук, доцент \\ Д. П. Арьков, кандидат технических наук, дочент
}

Волгоградский государственный аграрный университет, г. Волгоград

Дата поступления в редакцию 20.08.2021

Дата принятия к печати 09.11.2021

Аннотация. Рассматривается проблема применения композитной арматуры в гидротехническом строительстве, а именно при устройстве противофильтрационных одежд магистральных оросительных каналов оросительно-обводнительных систем. Приводятся данные о потерях воды при транспортировке в оросительных системах, а также потребности в противофильтрационных одеждах оросительных систем Волгоградской и Астраханской областей. Описаны положительные и отрицательные аспекты использования неметаллической композитной арматуры (НКА), приведены сравнительные прочностные расчеты плит с армированием неметаллической композитной арматурой разных технологий производства, сделаны выводы о перспективах применения НКА в гидротехническом строительстве.

Актуальность. Водная стратегия Российской Федерации требует исключить потери пресной воды, чему препятствуют такие факторы, как критический износ мелиоративных систем, ухудшение состояния мелиорируемых земель, особенно в зоне магистральной транспортирующей сети. Хорошо зарекомендовавшей себя противофильтрационной технологией является использование многослойных противофильтрационных одежд, включающих противофильтрационный полимерный и защитный железобетонный слой. Высокая потребность в железобетонных элементах противофильтрационной защиты требует применения инженерных решений для их удешевления и продления срока эксплуатации, чему препятствует высокая цена на сталь. Таким образом, исследования, направленные на замещение дорогостоящей стали на более дешевые и практичные в гидротехническом строительстве аналоги, представляют практический интерес. Объект. Объектом исследования является защитный слой противофильтрационных одежд магистральных каналов оросительных систем. Цель. Определение возможности использования неметаллической композитной арматуры для армирования канальных плит, используемых в качестве защитного слоя в каналах оросительных систем. Материалы и методы. В работе использовалась общенаучная методология с методами эмпирического (наблюдение, описание, сравнение, измерение) и теоретического (анализ и синтез) уровней. Результаты и выводы. На основании прочностных характеристик неметаллической композитной арматуры с использованием принятых методик произведен подбор сечений рабочей арматуры для плит наиболее востребованного форм-фактора, определен наиболее подходящий вид композитной арматуры. Показано преимущество применения НКА для данного элемента гидротехнических сооружений, даны рекомендации для ее использования.

Ключевые слова: противофильтрационная облицовка каналов, оросительные системы, магистральные каналь, неметаллическая композитная арматура.

Цитирование. Семененко С. Я., Марченко С. С., Арьков Д. П. Конструирование канальных

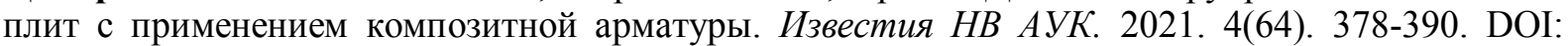
10.32786/2071-9485-2021-04-38. 
Авторский вклад. Все авторы настоящего исследования принимали непосредственное участие в сборе и подготовке материала, проведении расчетов и анализе результатов данного исследования. Все авторы настоящей статьи одобрили представленный окончательный вариант.

Конфликт интересов. Авторы заявляют об отсутствии конфликта интересов.

Введение. Оросительные каналы выполняют важнейшую функцию оросительной системы, а именно осуществляют транспортировку оросительной воды к орошаемым землям. Однако необходимо отметить, что оросительные каналы, построенные в 60-80 годы прошлого века, имеют значительный физический и моральный износ. Возрастающий износ каналов приводит к ежегодному увеличению затрат на текущий ремонт, что, в свою очередь, требует более совершенных и экономичных вариантов их восстановления $[6,7]$.

Свойства полиэфиров, фенолов, эпоксидов, детально изученные в США после 1970 года, создали основу для появления неметаллической (композитной) арматуры (НКА), отличающуюся более высокими показателями упругости, разрыва, плотности, в некоторых случаях не уступающую металлу и по другим свойствам [3, 9].

В Европе активное применение неметаллической арматуры пришлось на начало 80-х годов, в Японии - с середины 90-х, но крупнейшим потребителем с 90-х годов и до настоящего времени является Китай, использующий её в самых различных отраслях.

Однако считается, что создание неметаллической арматуры и изучение ее свойств первоначально было осуществлено в СССР в середине 60-х годов прошлого столетия. В 70-е годы началось уже широкое её применение в строительстве опорных сооружений, пролётных сооружений мостов, в ячеистых бетонах, в конструкциях крепления откосов, в морском гидротехническом строительстве $[5,11,13]$.

При этом парадоксально, но в гидромелиоративном строительстве до настоящего времени неметаллическая арматура применяется крайне мало, особенно с учетом всёвозрастающих объёмов ввода оросительно-обводнительных и осушительных систем нового поколения и перспектив, заложенных в Государственной программе эффективного вовлечения в оборот земель сельскохозяйственного назначения и развития мелиоративного комплекса, предусматривающих, в том числе, реконструкцию транспортирующих элементов оросительно-осушительных систем, заключающуюся в восстановлении и/или устройстве противофильтрационных облицовок каналов.

Своевременность принятия данной программы обусловлена несколькими насущными проблемами, а именно:

1. Требованиями экономного расходования природных пресных вод, обозначенными в Водной стратегии Российской Федерации.

2. Критическим возрастом гидромелиоративных систем, приближающимся к нормативному жизненному циклу, т.к. основная масса оросительных систем была введена в строй $40 \ldots 60$ лет назад.

3. Ухудшением мелиоративного состояния орошаемых земель, особенно в зоне влияния магистральной транспортирующей и распределительной сети.

4. Функциональными требованиями цифровых технологий при управлении мелиоративным комплексом.

Низкий технический уровень устройства и значительный износ инженерных оросительных систем приводят к потерям до $5 \mathrm{~km}^{3} /$ год природных пресных вод. При этом из транспортирующей сети на неинженерных системах теряется около 70-80 \% поданной в голове системы воды, а в инженерных системах на долю фильтрации из каналов приходится $25-30 \%[1,2,10]$. 
Дискретность уровней воды в каналах, низкий технический уровень противофильтрационных мероприятий на оросительных системах повышают потери воды, инициируют подъём уровня грунтовых вод, приводя к вторичному засолению и заболачиванию особо ценных орошаемых земель и сопряженных агроландшафтов, снижая их продуктивность.

Коэффициент полезного действия оросительной системы, основной показатель эффективности её работы, уменьшается, что приводит к увеличению энергетических и финансовых затрат на подачу воды.

Существующие мероприятия по борьбе с фильтрацией воды из каналов можно условно сгруппировать:

1. Наименее затратные - механическое уплотнение ложа канала, оглеение, диспергирование и др;

2. Затратные - искусственная кольматация русла канала;

3. Более затратные - применение плёнок, геомембран, бентонитовых глин и др.;

4. Дорогие - монолитное бетонирование русла канала гидротехническим бетоном и наиболее индустриальное мероприятие - укладка железобетонных канальных плит на однослойную или многослойную водонепроницаемую плёнку.

В последних, наиболее дорогих, такая многослойная конструкция противофильтрационного экрана работает крайне эффективно - водонепроницаемая плёнка защищает от фильтрации, а железобетонные плиты защищают плёнку от механического воздействия и ультрафиолетового излучения.

С точки зрения только эффективности борьбы с фильтрацией, наиболее приемлемым является применение монолитного гидротехнического бетона $[4,8]$.

Однако недостатки - безводные территории мест строительства, сезонность строительных работ, сложность (а порой и невозможность) работы на действующих оросительных системах, необходимость передвижной индустрии строительных материалов - делают данную технологию неприемлемой по технико-экономическим показателям.

Вышеперечисленные недостатки исключаются применением для облицовки каналов плоских тонкостенных плит с предварительно напряжённой металлической арматурой, обладающих достаточным запасом прочности и устойчивости.

Такие плиты с расчётными размерами длины 4-9 м, ширины 0,6-3,0 м и толщины 0,06 м изготавливаются таким образом, чтобы длина плиты полностью покрывала длину откоса. Индустриальное производство плит может быть налажено и на отдалённых объектах производства строительных материалов. Их монтаж технологически прост и возможен при отрицательных температурах, что крайне важно при ремонте, восстановлении и монтаже новых противофильтрационных одежд на старых неинженерных оросительных системах.

Потребность в таких плитах необычайно высока. По данным Управления «Волгоградмелиоводхоз», более 660 км магистральных каналов государственных оросительных систем нуждается в противофильтрационных одеждах (таблица 1).

Расчёты по укрупнённым показателям, приведённые к стандартным размерам плиты в соответствии с ГОСТ 22930-87, указывают на потребность в них в количестве около 1,9 млн штук, и это без учёта потребности в облицовке сбросных каналов.

Кроме того, с учетом в перспективе строительства обводного канала для обводнения Волго-Ахтубинской поймы протяжённостью 32 км и расходных характеристик 200 и $1000 \mathrm{~m}^{3} /$ сек в межень и половодье соответственно, проектные разработки которого стали доступны для научной общественности, провизорные расчёты показывают необходимость в плитах в количестве около 90 тыс. штук. 
Таблица 1 - Наличие и потребность противофильтрационных облицовок на каналах оросительных систем Волгоградской области

Table 1 - Availability and need of anti-filtration cladding on the canals of irrigation systems of the Volgograd region

\begin{tabular}{|c|c|c|c|c|c|}
\hline \multirow[b]{2}{*}{ № } & \multirow{2}{*}{$\begin{array}{c}\text { Наименование ороситель- } \\
\text { ной системы / } \\
\text { Name of the irrigation sys- } \\
\text { tem }\end{array}$} & \multirow{2}{*}{$\begin{array}{c}\text { Протяжённость магистральных } \\
\text { каналов, всего, км / The length of } \\
\text { the main canals, total, km }\end{array}$} & \multirow{2}{*}{$\begin{array}{c}\text { В том числе } \\
\text { имеют обли- } \\
\text { цовку, } \\
\text { км / Including } \\
\text { with cladding, } \\
\text { km }\end{array}$} & \multicolumn{2}{|c|}{$\begin{array}{c}\text { Потребность / } \\
\text { Requirement }\end{array}$} \\
\hline & & & & км / km & $\%$ \\
\hline 1 & $\begin{array}{l}\text { Большая Волгоградская } \\
\text { Bolshaya Volgogradskaya }\end{array}$ & 78,50 & 50,00 & 28,5 & 36,3 \\
\hline 2 & $\begin{array}{l}\text { Среднеахтубинская } \\
\text { Sredneakhtubinskaya }\end{array}$ & 22,60 & 10,20 & 12,4 & 54,9 \\
\hline 3 & $\begin{array}{l}\text { Городищенская } \\
\text { Gorodishchenskaya }\end{array}$ & 85,12 & 66,02 & 19,1 & 22,4 \\
\hline 4 & $\begin{array}{l}\text { Калачёвская } \\
\text { Kalachevskaya }\end{array}$ & 9,90 & 9,57 & 0,33 & 3,3 \\
\hline 5 & Оленьевкая Olenevskaya & 6,99 & 5,30 & 1,69 & 24,2 \\
\hline 6 & $\begin{array}{l}\text { Генераловская } \\
\text { Generalovskaya }\end{array}$ & 69,54 & 4,65 & 64,89 & 93,3 \\
\hline 7 & $\begin{array}{l}\text { Котельниковская } \\
\text { Kotelnikovskaya }\end{array}$ & 12,77 & 12,77 & 0,0 & 0,0 \\
\hline 8 & Тажинская Tazhinskaya & 30,00 & 18,80 & 11,2 & 37,3 \\
\hline \begin{tabular}{|l|}
9 \\
\end{tabular} & Ленинская Leninskaya & 130,66 & 0,00 & 130,66 & 100,0 \\
\hline 10 & $\begin{array}{l}\text { Волго-Ахтубинская Volga- } \\
\text { Akhtubinskaya }\end{array}$ & - & - & - & - \\
\hline 11 & Кисловская Kislovskaya & 111,27 & 75,76 & 35,51 & 31,9 \\
\hline 12 & Заволжская Zavolzhskaya & 99,42 & 99,42 & 0,0 & 0,0 \\
\hline 13 & $\begin{array}{l}\text { Палласовская } \\
\text { Pallasovskaya }\end{array}$ & 202,85 & 0,00 & 202,85 & 100,0 \\
\hline 14 & Иловатская Ilovatskaya & 4,20 & 4,20 & 0,0 & 0,0 \\
\hline 15 & $\begin{array}{l}\text { Райгородская } \\
\text { Raygorodskaya }\end{array}$ & 124,44 & 5,09 & 119,35 & 95,9 \\
\hline 16 & $\begin{array}{l}\text { Варваровская } \\
\text { Varvarovskaya }\end{array}$ & 39,78 & 4,90 & 34,88 & 87,7 \\
\hline 17 & $\begin{array}{l}\text { Ильмень-Суворовская } \\
\text { Ilmen-Suvorovskaya }\end{array}$ & 13,30 & 13,30 & 0,0 & 0,0 \\
\hline & Итого Total & 1041,34 & 379,98 & 661,36 & 63,5 \\
\hline
\end{tabular}

Оросительные системы Астраханской области, такие как КалмыкскоАстраханская рисовая, Ушаковская рисовая и др., также не имеют противофильтрационных одежд.

Однако, при многих положительных качествах, рассматриваемые плиты имеют и некоторые недостатки, основным из которых является наличие металлической арматуры, что является сдерживающим фактором для их широкого использования с учетом постоянно увеличивающейся стоимости металла.

В настоящее время в зависимости от марки стали и состава композита арматуры стоимость 1 п.м. составляет: стальной - 64,0-208,0 руб.; композитной - 29,8-39,6 руб., т.е. стоимость стальной превышает стоимость композитной от 2,1 до 5,3 раза, более того, полимерная арматура обладает меньшим весом, не вступает в реакцию с водой и не поддаётся коррозии. 
Задачей исследования является разработка новых типов плит для облицовки оросительных каналов мелиоративных систем, снижение их стоимости и увеличение несущей способности на основе теоретического и экспериментального изучения их работы.

В работе проведены конструирование и расчёт канальных облицовочных плит, где вместо металлической арматуры применяется композитная с различными химическими и физическими свойствами.

Ограничения применимости композитной арматуры основывается на необратимости изменения водно-механических свойств полимерной матрицы при высоких температурах (например, при пожаре), когда наступает процесс стеклования. Температура стеклования для НКА зависит от типа матрицы и находится в диапазоне от 70 до 175 градусов $[1,11,13]$. Однако данная проблема не является актуальной для конструкций мелиоративных каналов.

Для НКА коэффициент надежности по материалу установлен только в европейских нормах. В итальянских нормах CNR-DT 203 установлено значение коэффициента $\gamma=1,5$ для расчетов по первому предельному состоянию и 1,0 для второго. В бюллетене fib и ModelCode (2010) предложено для первого предельного состояния принимать значение коэффициента надежности $\gamma$ не менее 1,25 . В нормах ACI коэффициент $\gamma_{\mathrm{R}}$ как таковой отсутствует, однако нормативное (гарантированное производителем) значение определяется с обеспеченностью 0,9986 (3б), при этом дополнительно учитывается обобщенный коэффициент надежности (запаса) $\varphi=0,5-0,7$.

Материалы и методы. В исследовании применялись общенаучные методы познания, такие как анализ и синтез различных уровней с применением апробированных методов расчета и конструктивно-технологических решений для создания и ремонта железобетонных облицовок мелиоративных каналов с целью снижения стоимости и потерь воды на фильтрацию из гидромелиоративных систем при транспортировке воды. Для исследования возможности применения НКА рассмотрена плита марки ПКН60.20, форма и размеры плиты, а также её показатели материалоемкости приняты в соответствии с действующими нормативными государственными требованиями, такими как ГОСТы, СНиПы, СП.

Основные показатели плиты представлены в таблице 2.

Таблица 2 - Показатели материалоемкости плиты ПКН60.20

Table 2 - Indicators of the material capacity of the PKN60.20 plate

\begin{tabular}{|c|c|c|c|c|c|c|}
\hline $\begin{array}{c}\text { Марка } \\
\text { Плиты / } \\
\text { Grade of the } \\
\text { plate }\end{array}$ & \multicolumn{2}{|c|}{$\begin{array}{c}\text { Основные размеры плиты, мм / } \\
\text { Main dimensions of the plate, mm }\end{array}$} & \multicolumn{2}{|c|}{$\begin{array}{c}\text { Paсход материала / } \\
\text { Material consumption }\end{array}$} & $\begin{array}{c}\text { Масса плиты } \\
\text { (справочная), } /\end{array}$ \\
\cline { 2 - 7 } & $l$ & $h$ & $a_{l}$ & Бетон, $\mathrm{m}^{3}$ & Сталь, кг & $\begin{array}{c}\text { Plate weight (ref- } \\
\text { erence), } \mathrm{t}\end{array}$ \\
\hline ПКН60.20 & 6000 & 2000 & 1250 & 0,72 & 29,7 & 1,80 \\
\hline
\end{tabular}

Определение прочности и трещиностойкости плит по достижении бетоном прочности на сжатие в проектном возрасте выполняют нагружением. Бетон тяжелого класса B22,5 $\left(\mathrm{R}_{\mathrm{b}}=12,5 \mathrm{MПа}\right)$, напрягаемая арматура класса Bp-II $\left(\mathrm{R}_{\mathrm{s}}=1045 \mathrm{MПa}\right), 7$ стержней в нижней части, 6 с верху.

Схема опирания и загружения плиты при испытании ее нагружением приведена на рисунке 1 , где $\mathrm{a}_{1}$ - расстояние от края плиты до монтажных петель.

Контрольная нагрузка при испытании плиты на прочность и трещиностойкость $\mathrm{q}=$ 1,62 кПа (165 кг/м²), нагрузка при определении ширины раскрытия трещин плиты равна 85 \% контрольной. Контрольная ширина раскрытия трещин при испытании плиты по трещиностойкости не должна превышать 0,2 мм. Положение стержней напрягаемой арматуры и арматурных каркасов представлено на рисунке 2. 

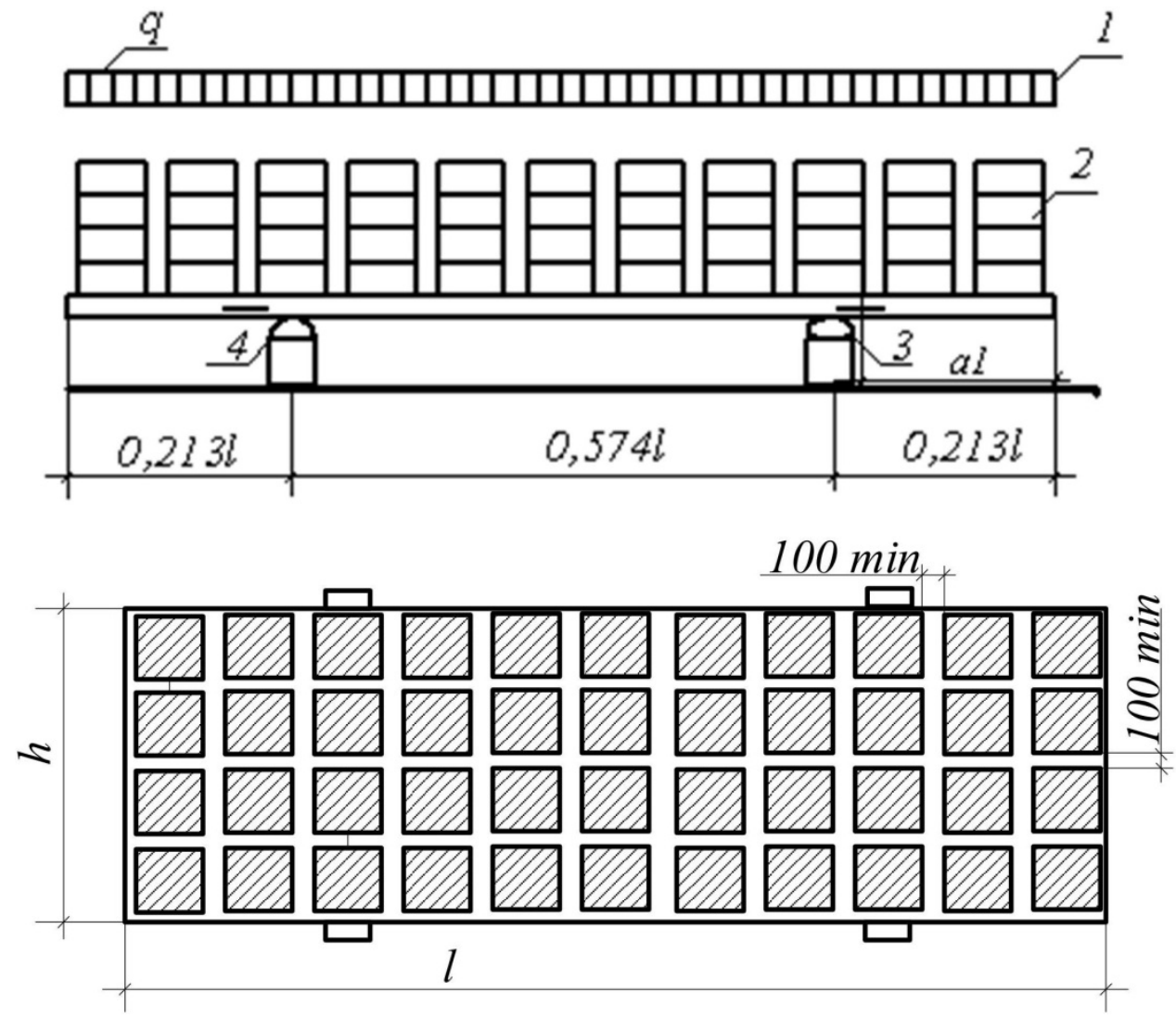

Рисунок 1 - Схема загружения плиты при испытании:

1 - теоретическая схема нагрузки; 2 - нагрузка; 3 - подвижная опора; 4 - неподвижная опора

Figure 1 - Diagram of loading the plate during the test:

1 - theoretical load diagram; 2 - load; 3 - movable support; 4 - fixed support

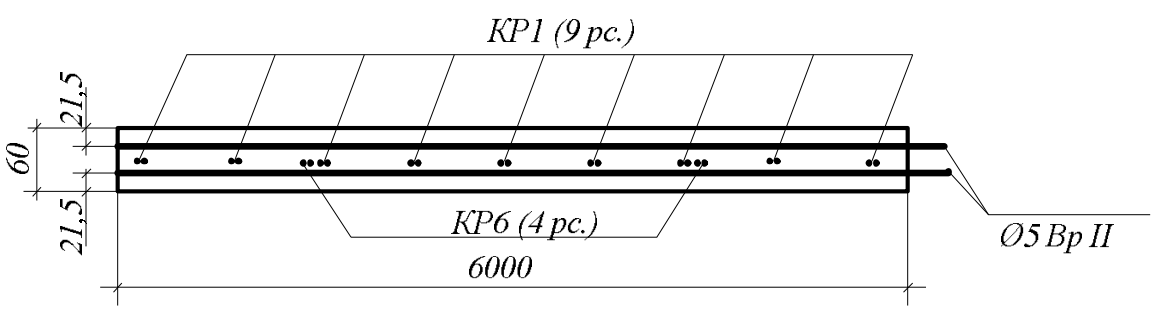

Рисунок 2 - Армирование плиты ПКН60.20, продольный разрез

Figure 2 - Reinforcement of the PKN60.20 plate, longitudinal section

Спецификация и выборка напрягаемой арматуры на одну плиту приведены в таблице 3.

Таблица 3 - Спецификация и выборка напрягаемой арматуры на одну плиту

Table 3 - Specification and selection of tensioned fittings per plate

\begin{tabular}{|c|c|c|c|c|c|c|}
\hline \multirow[b]{2}{*}{$\begin{array}{c}\text { Марка плиты / } \\
\text { Grade of the } \\
\text { plate }\end{array}$} & \multirow[b]{2}{*}{$\begin{array}{c}\text { Позиция/ } \\
\text { Position }\end{array}$} & \multirow[b]{2}{*}{$\begin{array}{l}\text { Диаметр, } \\
\text { мм/ Diame- } \\
\text { ter, mm }\end{array}$} & \multirow{2}{*}{$\begin{array}{l}\text { Длина, } \\
\text { мм/ } \\
\text { Length, } \\
\text { mm }\end{array}$} & \multirow[b]{2}{*}{$\begin{array}{c}\text { Количество/ } \\
\text { Quantity }\end{array}$} & \multicolumn{2}{|c|}{ Мacca, кг /Weight, kg } \\
\hline & & & & & $\begin{array}{l}\text { одной пози- } \\
\text { ции / one posi- } \\
\text { tion }\end{array}$ & всего / total \\
\hline ПКН60.20 & 1 & 5 & 6140 & 13 & 0,95 & 12,35 \\
\hline
\end{tabular}


Напряжение в напрягаемой арматуре, контролируемое по окончании натяжения, 804,1МПа. Для нахождения изгибающего момента и поперечной силы при расчёте необходимо учитывать собственный вес плиты, определяемый по формуле 1:

$$
\mathrm{q}_{\text {constr }}=\gamma_{\mathrm{b}} \times 1 \times \mathrm{h} \times \gamma_{\mathrm{f}}=25 \mathrm{\kappa} \mathrm{H} / \mathrm{M}^{3} \times 6 \mathrm{M} \times 0,06 \mathrm{M} \times 1,1=9,9 \kappa \mathrm{H} / \mathrm{M},
$$

где $\gamma_{\mathrm{b}}$ - удельный вес железобетона, 1 - длина плиты, $\mathrm{h}$ - толщина (высота), $\gamma_{\mathrm{f}}-$ коэффициент надежности по нагрузке.

Суммарная нагрузка на плиту будет определяться по формуле 2:

$$
\mathrm{q}=\mathrm{q}_{\text {constr }}+\mathrm{q}_{\text {исп }}=9,9+1,62=11,52 \kappa \mathrm{H} / \mathrm{м} .
$$

Используя известные выражения строительной механики, определили наибольший изгибающий момент и поперечные силы, на рисунке 3 они представлены графически.

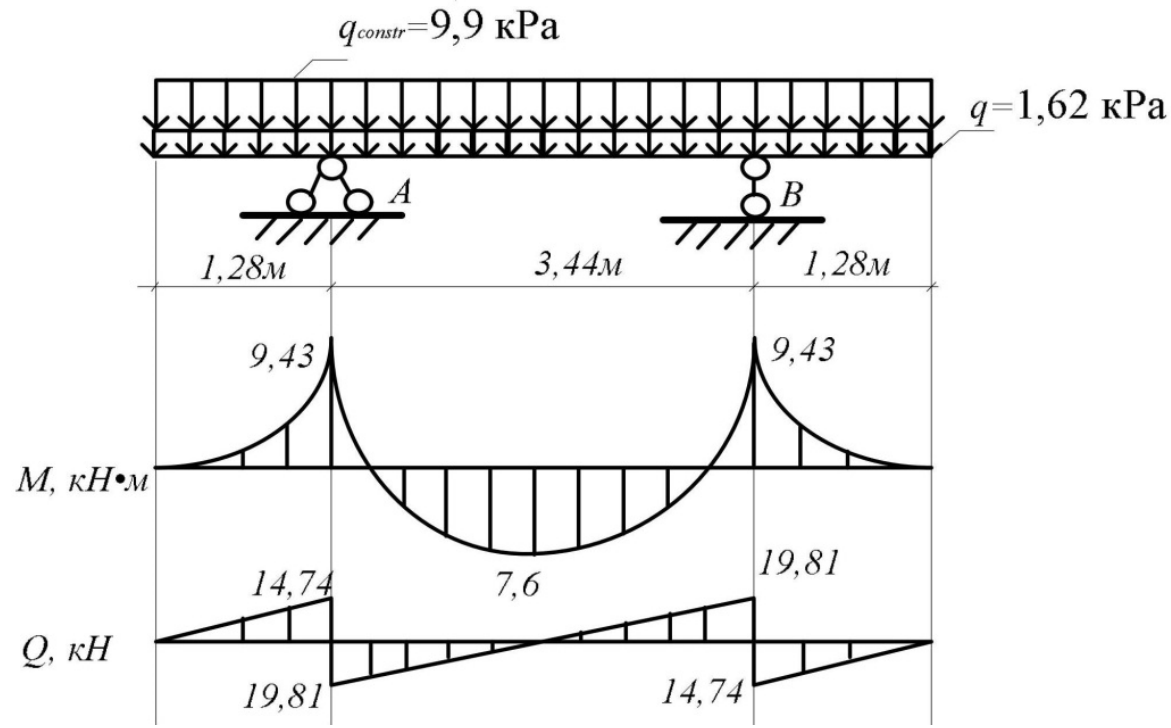

Рисунок 3 - Расчётная схема, эпюры изгибающих моментов и поперечных сил

Figure 3 - Calculation scheme, diagrams of bending moments and transverse forces

Результаты и обсуждение. Подбор сечений рабочей неметаллической арматуры плиты произведён на основании прочностных характеристик композитной арматуры, представленных в таблице 4.

Таблица 4 - Характеристики НКА при растяжении

Table 4 - Characteristics of non-metallic composite reinforcement under tension

\begin{tabular}{|c|c|c|c|c|}
\hline $\begin{array}{c}\text { Наименование показателя / } \\
\text { Name of the indicator }\end{array}$ & $\begin{array}{c}\text { Ед. } \\
\text { Изм. / } \\
\text { ed.ed. }\end{array}$ & $\begin{array}{c}\text { Стеклокомп. АСК } \\
\text { /Glass composite } \\
\text { reinforcement }\end{array}$ & $\begin{array}{c}\text { Углекомп. АУК / } \\
\text { Carbon-composite } \\
\text { reinforcement }\end{array}$ & $\begin{array}{c}\text { Арамидокомп. } \\
\text { ААК/ Aramid } \\
\text { Composite rein- } \\
\text { forcement }\end{array}$ \\
\hline $\begin{array}{c}\text { Предел прочности } \\
\text { при растяжении / Ultimate } \\
\text { tеnsile strength }\end{array}$ & $\begin{array}{c}\mathrm{MПa} \mathrm{/} \\
\mathrm{MPa}\end{array}$ & $450-1600$ & $600-3500$ & $1000-2500$ \\
\hline $\begin{array}{c}\text { Модуль упругости } \\
\text { при растяжении / Тепsile } \\
\text { тодulus of elasticity }\end{array}$ & $\begin{array}{c}\text { Гпа / } \\
\mathrm{GPa}\end{array}$ & $35-60$ & $100-580$ & $40-125$ \\
\hline $\begin{array}{c}\text { Предельная } \\
\text { относительная } \\
\text { деформация / Махітum } \\
\text { relative deformation }\end{array}$ & $\%$ & $1,2-3,7$ & $0,5-1,7$ & $1,9-4,4$ \\
\hline
\end{tabular}


Как наиболее распространённую, геометрически сходную с Вр -II принимаем стеклопластиковою арматуру диаметром 4,77 мм, площадью поперечного сечения $\mathrm{S}=$ $17,83 \mathrm{~mm}^{2} \mathrm{R}_{\mathrm{s}}=1100 \mathrm{H} / \mathrm{Mm}^{2}$. Определяем $\mathrm{h}_{0}$ - рабочую высоту сечения по формуле (3):

$$
\mathrm{h}_{0}=\mathrm{h}-\mathrm{a}_{\mathrm{sp}}=60-21,5=38,5 \mathrm{мм},
$$

где $\mathrm{a}_{\mathrm{sp}}-$ расстояние от равнодействующей усилий в арматуре до ближайшей грани сечения.

При расчете на прочность напряженных конструкций с композитной арматурой необходимо учитывать предварительные напряжения, а также их потери [3]. Для стеклопластиковой арматуры предварительные напряжения находятся по формуле 4:

$$
\sigma_{f p}=0,45 \cdot R_{f, n}=0,45 \cdot 1100=495 M \Pi a,
$$

где $R_{f, n}$ - сопротивление растяжению; потери от релаксации: $\sigma_{f p 2}=0,2 \cdot \sigma_{f p}=0,2 \cdot 495=$ $99 M$ М , потери от температурного перепада: $\sigma_{f p 3}=1,25 \cdot \Delta t=1,25 \cdot 65=78 M$ Па, потери от деформации стальной формы: $\sigma_{f p 4}=30 M \Pi a$.

Предварительное напряжение с учетом всех потерь найдем по формуле (5):

$$
\sigma_{s p}=495-99-78-30=288 \text { МПа. }
$$

Расчет прочности нормальных сечений бетонных конструкций с НКА следует производить в зависимости от соотношения между значением относительной высоты сжатой зоны $\xi=\frac{x}{h_{0}}$, определяемым из соответствующих условий равновесия, и значением граничной относительной высоты сжатой зоны $\xi_{R}$, при котором предельное состояние элемента наступает одновременно с достижением в растянутой арматуре напряжения, равного расчётному сопротивлению $R_{S}$

Значение $\xi_{R}$ определим по формуле:

$$
\xi_{R}=\frac{x_{R}}{h_{0}}=\frac{\omega}{1+\frac{\varepsilon_{f}}{\varepsilon_{b 2}}}
$$

где $\omega=0,8 ; \varepsilon_{b 2}$ принимаем по [4], равной 0,0035; $\varepsilon_{f}=\frac{R_{s}+400-\sigma_{s p}}{E_{s}}-$ расчетное значение предельных относительных деформаций композитной полимерной арматуры, $\sigma_{s p}-$ предварительное напряжение, $\mathrm{E}_{\mathrm{s}}$ - модуль упругости арматуры, $R_{S}$ - расчётное сопротивление арматуры.

Подставляя в выражение (6) необходимые величины, рассчитали, что $\xi_{R}=0,099$.

При расчете элемента в стадии предварительного обжатия усилие в напрягаемой арматуре вводится в расчет как внешняя продольная сила, равная:

$$
N_{p}=\left(\sigma_{s p}^{\prime}-330\right) A_{s p}^{\prime}+\sigma_{s p} \cdot A_{s p},
$$

где $\sigma_{s p}^{\prime}$ и $\sigma_{s p}-$ предварительные напряжения с учетом первых потерь в арматуре с соответствующей площадью $A_{s p}^{\prime}$ и $A_{s p}$.

Подставляя в выражение (7) необходимые величины, рассчитали усилие от предварительного обжатия $N_{p}=71248,68 \mathrm{H}$.

Учитывая величину $\xi_{R}=0,099$, определили высоту сжатой зоны бетона по следующей формуле:

$$
x=\frac{N_{p}+\mathrm{R}_{S} \mathrm{~A}_{s} \frac{1+\xi_{R}}{1-\xi_{R}}}{\mathrm{R}_{b} b+\frac{2 \mathrm{R}_{S} \mathrm{~A}_{S}}{h_{0}\left(1+\xi_{R}\right)}}
$$


Подставив значения, найдем высоту сжатой зоны $\mathrm{x}=6,8$ мм. Остается проверить выполнение условия прочности по моментам, момент от расчетной нагрузки равен:

$$
\mathrm{M}_{r}=R_{s} \cdot A_{s} \cdot\left(h_{0}-\frac{x}{2}\right)=17,45 \cdot 7 \cdot 1100 \cdot\left(38,5-\frac{6,8}{2}\right)=4,58 \cdot 10^{6} \mathrm{Hмм}
$$

$\mathrm{M}_{r}=4,58 \kappa \mathrm{Mм}<\mathrm{M}=9,43 \kappa \mathrm{Hм}$.

Условия прочности не выполняется, если принять стеклопластиковую арматуру диаметром 8 мм, то

$$
\mathrm{M}_{r}=R_{s} \cdot A_{s} \cdot\left(h_{0}-\frac{x}{2}\right)=40,7 \cdot 7 \cdot 1100 \cdot\left(38,5-\frac{16,7}{2}\right)=9,45 \cdot 10^{6} \mathrm{HмM}
$$

$\mathrm{M}_{r}=9,45 \kappa \mathrm{M}>\mathrm{M}=9,43 \kappa \mathrm{M}-$ условие прочности выполняется.

Аналогичные расчёты по подбору сечения при соответствующих принятых характеристиках арматуры выполнены для углекомпозитной и арамидокомпозитной арматуры. Результаты расчётов, проведённых в соответствии с требованиями ГОСТ, приведены в таблице 5.

Таблица 5 - Минимальный диаметр НКА для армирования плит ПКН60.20

Table 5 - Minimum diameter of the NCR for reinforcement of PKN60.20 plates

\begin{tabular}{|l|c|c|c|c|}
\hline \multicolumn{1}{|c|}{$\begin{array}{c}\text { Наименование } \\
\text { показателя }\end{array}$} & $\begin{array}{c}\text { Ед. } \\
\text { Изм. / } \\
\text { ed.ed. }\end{array}$ & $\begin{array}{c}\text { Стеклокомп. АСК / } \\
\text { Glas composite rein- } \\
\text { forcement }\end{array}$ & $\begin{array}{c}\text { Углекомп. АУК / } \\
\text { Carbon-composite } \\
\text { reinforcement }\end{array}$ & $\begin{array}{c}\text { Арамидокомп. } \\
\text { AАК / Aramid Com- } \\
\text { posite reinforcement }\end{array}$ \\
\hline $\begin{array}{l}\text { Предел прочности } \\
\text { при растяжении / Ulti- } \\
\text { mate tensile strength }\end{array}$ & $\begin{array}{c}\text { Мпа / } \\
\mathrm{MPa}\end{array}$ & 1100 & 1700 & 1500 \\
\hline $\begin{array}{l}\text { Модуль упругости } \\
\text { при растяжении/ Тensile } \\
\text { modulus of elasticity }\end{array}$ & $\begin{array}{c}\text { Гпа / } \\
\mathrm{GPa}\end{array}$ & 50 & 250 & 60 \\
\hline $\begin{array}{l}\text { Диаметр по сортаменту / } \\
\text { Diameter by grade }\end{array}$ & $\begin{array}{c}\mathrm{Mm} / \\
\mathrm{mm}\end{array}$ & 8 & 6 & 8 \\
\hline
\end{tabular}

Выводы. Для выбранной канальной плиты толщиной 60 мм возможно произвести замену стальной напрягаемой арматуры марки Вр-II Ø 5 мм на композитную стеклопластиковую арматуру Ø 8мм, в верхней и нижней зонах, а также уменьшить защитный слой бетона и, соответственно, толщину плиты, уменьшив при этом её вес и давление на откос канала, расчёт которых будет произведён и показан в следующих публикациях.

В полном объёме композитная арматура не заменит стальную в конструкциях, но займет определенный сегмент в мелиоративном строительстве, так как обладает многими достоинствами, основными из которых является её стоимость, устойчивость к коррозии и долговечность.

\section{Библиографический список}

1. Абдразаков Ф. К., Рукавишников А. А. Совершенствование технологии реконструкции оросительных каналов с применением инновационного материала // Оптимизация сельскохозяйственного землепользования и усиление экспортного потенциала АПК РФ на основе конвергентных технологий: материалы Международной научно-практической конференции, проведенной в рамках Международного научно-практического форума, посвященного 75-летию Победы в Великой Отечественной войне 1941-1945 гг. Волгоград: ФГБОУ ВО Волгоградский ГАУ, 2020. Том 3. С. 123-130. 


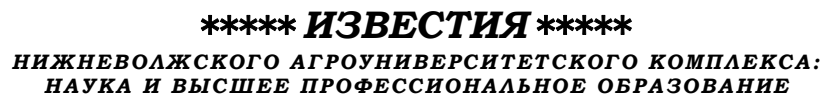

2. Абдразаков Ф. К. Ресурсосберегающие технологии и машины для интенсификации мелиоративного производства. Саратов: ФГБОУ ВО Саратовский государственный аграрный университет им. Н. И. Вавилова, 2019. 164 с.

3. Беккер А. Т., Уманский А. М. Перспективы применения композитной арматуры // Вестник Инженерной школы Дальневосточного федерального университета. 2018. № 2. С. 7.

4. Окольникова Г. Э., Курлин М., Йочич М. Способы повышения морозостойкости железобетонных конструкций из высокопрочного фибробетона // Системные технологии. 2021. № 38. C. 89-93.

5. Перспективы применения композитной арматуры в морском гидротехническом строительстве / А. В. Завгороднев [и др.] // Горный информационный бюллетень (научнотехнический журнал). 2014. № 54-9. С. 137-148.

6. Рукавишников А. А., Абдразаков Ф. К. Исключение непроизводительных потерь водных ресурсов из оросительной сети за счет использования инновационных облицовочных материалов // Аграрный научный журнал. 2019. С. 91-94.

7. Рукавишников А. А., Абдразаков Ф. К. Интенсификация мелиоративного производства путём совершенствования технологий реконструкции и строительства оросительных каналов // Мелиорация и водное хозяйство. 2019. С. 6-9.

8. Семененко С. Я., Марченко С. С. Экспериментальные испытания бетонных балок с композитной арматурой // Инновационные технологии в агропромышленном комплексе в современных экономических условиях: материалы международной научно-практической конференции. Волгоград, 2021. Том 3. С. 240-242.

9. Углепластики: технология получения и определение механических характеристик / В. Н. Манхиров [и др.] // Вестник БГУ. Химия. Физика. 2019. № 2-3. С. 12-19.

10. Compressive strength of lightweight expanded polystyrene basalt fiber concrete / G. Okolnikova [et al.] // International Conference on Modern Trends in Manufacturing Technologies and Equipment: Mechanical Engineering and Materials Science. 2020. V. 329.04010. https://doi.org/10.1051/matecconf/202032904010

11. Karbhari V. M., Chin J. W., Dunston D. Durability Gap Analysis for Fiber-Reinforced Polymer Composites in Civil Infrastructure // Journal of Composites for Construction. 2018. P. 238-247.

12. Kumahara S., Masuda Y., Tanano Y. Tensile Strength of Continuous Fiber Bar under High Temperature // International Symposium on Fiber-Reinforcement-Plastic Reinforcement for Concrete Structures. American Concrete Institute. 2017. V. 16. Pp. 278-283.

13. Wang N., Evans J. T. Collapse of Continuous Fiber Composite Beamat Elevated Temperatures // Journal of Composites. 2017. V. 37 (1). P. 56-61.

Conclusion. For the selected canal plate with a thickness of $60 \mathrm{~mm}$, it is possible to replace the steel tension reinforcement of the Bp-II grade with a diameter of $5 \mathrm{~mm}$, with composite fiberglass reinforcement $\varnothing 6 \mathrm{~mm}$., in the upper and lower zones, as well as to reduce the protective layer of concrete, and, accordingly, the thickness of the plate, while reducing its weight and pressure on the canal slope. Due to the fact that the corrosion resistance of fiberglass reinforcement is incomparably higher than steel, the protective layer of concrete and, accordingly, the thickness of the plate can be reduced. Polymer rods have a lower weight compared to metal. Their use allows you to reduce the load on the base. The material does not react with water and does not corrode.

In full, composite reinforcement will not replace steel in structures, but will occupy a certain segment in reclamation construction, since it has many advantages, the main of which are its cost, corrosion resistance and durability.

\section{References}

1. Abdrazakov F. K., Rukavishnikov A. A. Sovershenstvovanie tehnologii rekonstrukcii orositel'nyh kanalov s primeneniem innovacionnogo materiala // Optimizaciya sel'skohozyajstvennogo zemlepol'zovaniya i usilenie jeksportnogo potenciala APK RF na osnove konvergentnyh 


\section{***** H3BECTYЯ ***** \\ НИЖНЕВОАЖСКОГО АГРОУНИВЕРСИТЕТСКОГО КОМПАЕКСА: \\ НАУКА И ВЫСШЕЕ ПРОФЕССИОНААЬНОЕ ОБРАЗОВАНИЕ}

tehnologij: materialy Mezhdunarodnoj nauchno-prakticheskoj konferencii, provedennoj v ramkah Mezhdunarodnogo nauchno-prakticheskogo foruma, posvyaschennogo 75-letiyu Pobedy v Velikoj Otechestvennoj vojne 1941-1945 gg. Volgograd: FGBOU VO Volgogradskij GAU, 2020. Vol. 3. P. 123-130.

2. Abdrazakov F. K. Resursosberegayuschie tehnologii i mashiny dlya intensifikacii meliorativnogo proizvodstva. Saratov: FGBOU VO Saratovskij gosudarstvennyj agrarnyj universitet im. N. I. Vavilova, 2019. 164 p.

3. Bekker A. T., Umanskij A. M. Perspektivy primeneniya kompozitnoj armatury // Vestnik Inzhenernoj shkoly Dal'nevostochnogo federal'nogo universiteta. 2018. № 2. P. 7.

4. Okol'nikova G. \}., Kurlin M., Jochich M. Sposoby povysheniya morozostojkosti zhelezobetonnyh konstrukcij iz vysokoprochnogo fibrobetona // Sistemnye tehnologii. 2021. № 38. S. 89-93.

5. Perspektivy primeneniya kompozitnoj armatury v morskom gidrotehnicheskom stroitel'stve / A. V. Zavgorodnev [i dr.] // Gornyj informacionnyj byulleten' (nauchno-tehnicheskij zhurnal). 2014. № 54-9. P. 137-148.

6. Rukavishnikov A. A., Abdrazakov F. K. Isklyuchenie neproizvoditel'nyh poter' vodnyh resursov iz orositel'noj seti za schet ispol'zovaniya innovacionnyh oblicovochnyh materialov // Agrarnyj nauchnyj zhurnal. 2019. P. 91-94.

7. Rukavishnikov A. A., Abdrazakov F. K. Intensifikaciya meliorativnogo proizvodstva putjom sovershenstvovaniya tehnologij rekonstrukcii i stroitel'stva orositel'nyh kanalov // Melioraciya i vodnoe hozyajstvo. 2019. P. 6-9.

8. Semenenko S. Ya., Marchenko S. S. Jeksperimental'nye ispytaniya betonnyh balok s kompozitnoj armaturoj // Innovacionnye tehnologii v agropromyshlennom komplekse v sovremennyh jekonomicheskih usloviyah: materialy mezhdunarodnoj nauchno-prakticheskoj konferencii. Volgograd, 2021. Vol. 3. P. 240-242.

9. Ugleplastiki: tehnologiya polucheniya i opredelenie mehanicheskih harakteri-stik / V. N. Manhirov [i dr.] // Vestnik BGU. Himiya. Fizika. 2019. № 2-3. P. 12-19.

10. Compressive strength of lightweight expanded polystyrene basalt fiber concrete / G. Okolnikova [et al.] // International Conference on Modern Trends in Manufacturing Technologies and Equipment: Mechanical Engineering and Materials Science. 2020. V. 329.04010. https://doi.org/10.1051/matecconf/202032904010

11. Karbhari V. M., Chin J. W., Dunston D. Durability Gap Analysis for Fiber-Reinforced Polymer Composites in Civil Infrastructure // Journal of Composites for Construction. 2018. P. 238-247.

12. Kumahara S., Masuda Y., Tanano Y. Tensile Strength of Continuous Fiber Bar under High Temperature // International Symposium on Fiber-Reinforcement-Plastic Reinforcement for Concrete Structures. American Concrete Institute. 2017. V. 16. Pp. 278-283.

13. Wang N., Evans J. T. Collapse of Continuous Fiber Composite Beamat Elevated Temperatures // Journal of Composites. 2017. V. 37 (1). P. 56-61.

\section{Author's Information}

Semenenko Sergey Yakovlevich, Doctor of Agricultural Sciences, Professor, Volgograd Agrarian University (40002, Russian Federation, Volgograd, Universitetskiy Avenue, 26), phone 8(961)-068-52-07

Marchenko Sergey Sergeevich, Candidate of Technical Sciences, Associate Professor of the Department of Information Systems and Technologies, Volgograd Agrarian University (40002, Russian Federation, Volgograd, Universitetskiy Avenue, 26), phone 8(909)-377-95-99

Ar'kov Dmitrij Petrovich, Candidate of Technical Sciences, Associate Professor of the Department of Information Systems and Technologies, Volgograd Agrarian University (40002, Russian Federation, Volgograd, Universitetskiy Avenue, 26), phone 8(917)722-19-44

\section{Информация об авторах}

Семененко Сергей Яковлевич, ФГБОУ ВО «Волгоградский государственный аграрный университет» (РФ, 400002, г. Волгоград, пр. Университетский, д.26), доктор сельскохозяйственных наук, професcop, e-mail: sergeysemenenko@list.ru, телефон 8(961)-068-52-07 


\title{
***** H3BECTKЯ ***** \\ НИЖНЕВОАЖСКОГО АГРОУНИВЕРСИТЕТСКОГО КОМПАЕКСА: \\ НАУКА И ВЫСШЕЕ ПРОФЕССИОНААЬНОЕ ОБРАЗОВАНИЕ
}

Марченко Сергей Сергеевич, ФГБОУ ВО «Волгоградский государственный аграрный университет» (РФ, 400002, г. Волгоград, пр. Университетский, д.26), кандидат технических наук, доцент, еmail: marchenkosergey@mail.ru, телефон: 8(909)377-95-99.

Арьков Дмитрий Петрович, ФГБОУ ВО «Волгоградский государственный аграрный университет» (РФ, 400002, г. Волгоград, пр. Университетский, д.26), кандидат технических наук, доцент, е-таil: arkov-dmitriy@rambler.ru, телефон: 8(917)722-19-44.

\section{IMPROVING THE RELIABILITY OF CONCRETE ELEMENTS}

DOI: $10.32786 / 2071-9485-2021-04-39$ OF RECLAMATION SYSTEMS

\author{
E. V. Vasilyeva ${ }^{1}$, V. M. Fedorov ${ }^{2}$ \\ ${ }^{1}$ South Russian State Polytechnic University named after M.I. Platov, Novocherkassk \\ ${ }^{2}$ Novocherkassk Engineering and Land Reclamation Institute named after A. K. Kortunov- \\ branch of the Don State Agrarian University, Novocherkassk
}

Received 19.08.20121

Submitted 29.11.2021

\begin{abstract}
Introduction. Reclamation systems play an important role in the life of society. Through channels and pipelines, water is supplied to arid lands and fields of arid and low-water areas, distributed over them, ensuring the creation of agricultural production, expanding livestock and poultry farming, increasing crop yields. The purpose of the study was to increase the operational reliability of reinforced concrete elements (slabs, pipes) of reclamation systems through the use of limestone components in concretelimestone crushed stone and limestone dust. Materials and methods. Concrete compositions for reinforced concrete slabs were compared with the use of crushed stone from sandstone and limestone, standard samples-cubes were formed from concrete mixtures on a vibrating table, then they were subjected to heat and moisture treatment, and to assess operational qualities, they were tested for strength. Limestone dust was introduced into the concrete mixture for centrifuged pipes, instead of a part of sand (cement). The amount of water was selected experimentally, from the conditions for obtaining equally mobile mixtures, standard prisms and cylinders were formed from them, they were subjected to heat and moisture treatment and, to assess operational reliability, bending, compression, splitting tests were performed. Results and conclusions. The conducted studies have shown that the use of limestone crushed stone slabs in concrete increases, on average, the strength indicators by $20 \%$, and the addition of limestone dust reduces the consumption of cement by $25 \%$, without worsening the strength indicators of centrifuged concrete. When dust is added in the amount of $20-30 \%$ of the cement mass, the strength indicators of the concrete increase by $25-40 \%$, without increasing the cement consumption, thereby increasing the quality and reliability of pipes. The expediency of using limestone crushed stone and limestone dust in concrete to improve the operational qualities and reliability of reinforced concrete slabs and pipes, widely used in the country's reclamation systems, is justified. Production tests have confirmed that concrete based on limestone components provides increased strength, crack resistance and water resistance, which ensures the safety, reliability and durability of reclamation systems.
\end{abstract}

Keywords: reclamation systems, reliability, reinforced concrete slabs and pipes, concrete aggregates, strength, defects in concrete, cement hydration, limestone rubble and dust, adhesion of cement stone and fillers, diffuse layer, crystal bonds, standard samples, strength indicators.

Citation. Vasilyeva E.V., Fedorov V. M. Improving the reliability of concrete elements of reclamation systems. Proc. of the Lower Volga Agro-University Comp. 2021. 4(64). 390-400 (in Russian). DOI: 10.32786/2071-9485-2021-04-39.

Author's contribution. All the authors of this study were directly involved in the planning, implementation or analysis of this study. All the authors of this article have read and approved the final version presented.

Conflict of interest. The authors declare that there is no conflict of interest. 